\title{
Amelioration of CIA by Asarinin Is Associated to a Downregulation of TLR9/NF- $\kappa$ B and Regulation of Th1/Th2/Treg Expression
}

\author{
Qiaomei Dai, ${ }^{a}$ Meiqiao Wang, ${ }^{a}$ Yaozhang $\mathrm{Li}^{a},{ }^{a}$ and $\mathrm{Ji} \mathrm{Li}{ }^{*}, b$ \\ ${ }^{a}$ Department of Pathology, Heilongjiang University of Chinese Medicine; Harbin 150040, China: and ${ }^{b}$ Department of \\ Chinese Formulae, Heilongjiang University of Chinese Medicine; Harbin 150040, China. \\ Received January 30, 2019; accepted April 14, 2019; advance publication released online April 23, 2019
}

To study the role of asarinin on collagen-induced arthritis (CIA) and its treatment mechanism on dendritic cells (DCs) and T cells. Before the onset of arthritis, asarinin were given orally to CIA mouse. Macroscopic scoring and micrometer caliper measurement were used to assess arthritis. The occurrence of cartilage destruction and bone erosion were assessed by histology of knee. Sandwich enzyme-linked immunosorbent assay (ELISA) and PCR were used to assess the level of cytokines in hindpaw and arthritic joint. The CD11c MicroBeads were employed to isolate CD11c+ cells from the spleen. Quantitative PCR was used to determine DCs surface molecules of spleen. Macroscopic score and the frequency of arthritis were inhibited by asarinin. Swelling of hindpaws, inflammatory cell infiltration in the synovium, cartilage destruction, and bone erosion were delayed with asarinin. Asarinin treatment suppressed the expression of $T$ helper type 1 (Th1) cytokines and increased the levels of Th2 cytokines (interleukin (IL)-10), transforming growth factor (TGF)- $\beta$ and Foxp3 in the synovium and hindpaw, however T-bet mRNA levels in synovium decreased. Lower expression of toll-like receptor 9 (TLR9) and nuclear factor-kappaB (NF- $\kappa$ B) were found in DCs after asarinin treatment. There was no difference in the expression of intercellular cell adhesion molecule1(ICAM-1), OX40-L, and 4-1BBL in spleen DCs between the asarinin group and model control group. Asarinin can treat CIA. TLR9/NF- $\kappa$ B pathway may be involved in the asarinin treatment of CIA by skewing the balance of Th1/Th2/regulatory T (Treg) to a Th2 type.

Key words asarinin; collagen induced arthritis; dendritic cell; regulatory $\mathrm{T}$ cell; $\mathrm{T}$ helper cell

\section{INTRODUCTION}

Rheumatoid arthritis (RA) is a complex autoimmune disease that mainly affects the synovial tissue of the joints of patients, and leads to chronic immune inflammatory reaction in long-term development, and eventually leads to cartilage and bone erosion and joint destruction. ${ }^{1)}$ The cytokines involved in the chronic synovial inflammation included inflammatory cytokines and anti-inflammatory cytokines, and $\mathrm{T}$ cells play a critical role on cytokine production. Although the roles of $\mathrm{T}$ cells in the pathogenesis of RA are not fully understood, T-helper 1 (Th1) cytokines (interferon- $\gamma($ IFN- $\gamma$ ), tumor necrosis factor- $\alpha$ (TNF- $\alpha$ ), interleukin-1 (IL-1)), Th2 cytokines (IL-4 and IL-10), Th17 cytokines (IL-17 and IL-22), and $\mathrm{CD} 4+\mathrm{CD} 25+$ FoxP3 + regulatory $\mathrm{T}$ cells (Treg cells) have been shown to be the contributing factors that interact with cell surface molecules to activate synovial inflammatory cells, synovial cells, and osteoclasts, leading to the inflammation and destruction of joint. ${ }^{1,2)}$ Transforming growth factor (TGF) $-\beta$ alone induces the Treg transcription factor Foxp3 and is essential for the development of Treg cells in the periphery. ${ }^{3)}$ The differentiation of $\mathrm{T}$ cells is mainly related to professional antigen presenting cells (dendritic cells (DCs)). When DCs detect pathogen-associated molecular patterns or damage-associated molecular patterns and antigen activation signals, they will enter a mature state and reach the secondary lymphoid organs and present the antigens to naive $\mathrm{T}$ cells, and drive naive $\mathrm{T}$ cells to differentiate into $\mathrm{Th}$ cells. ${ }^{4)}$

Type II collagen is the first collagen fiber identified to induce polyarticular lesions in the experiment, and causes ero- sive arthritis in DBA/1 mice and primates. This polyarticular lesion is called collagen-induced arthritis. Unlike the onset of RA, collagen-induced arthritis (CIA) is an arthritis that is induced by a strong heterologous antigen, but the erosion of articular cartilage and bone tissue was found in the CIA model, similar to the pathological changes in human RA, and the immune recognition of CII was similar to human RA. ${ }^{5-8)}$

XiXin, the dried roots and rhizomes of Asarum heterotropoides Fr. Schmidt var. mandshuricum (MAXIm.) Kitag., A.sieboldii MıQ. var. seoulense NAKAI, and A. sieboldii MIQ. (Aristolochiaceae), is a common herb used in China and other countries. Asarinin is one of major active chemical components isolated from Xixin with a molecular weight of 354.35 . Similar to its progenitor plant, asarinin has a variety of pharmacological properties, including antipyretic effects, antiinflammatory effects and immunosuppressive properties. ${ }^{9-12)}$

The pharmacological characteristics of asarinin prompted us to study the potential effect of asarinin on RA..$^{13)} \mathrm{T}$ cells and DCs are involved in the inflammatory response of RA, so we focus our research on the immunoregulatory effects of asarinin on CIA, and the possible roles of T cells and DCs in the pathological process of arthritis.

\section{MATERIALS AND METHODS}

Animals DBA/1 male mice were obtained from Shenyang Slac Laboratories (Shenyang, China). The age of 8-10 weeks of DBA/1 mice were immunized to make the CIA model. The mice used in this experiment were treated in accordance with the guidelines of the Animal Ethics Committee of Heilongji- 
ang University of Traditional Chinese Medicine.

Materials Freund's complete adjuvant (FCA) of Sigma and bovine type II collagen of Chondrex were purchased from Beijing Boleide Development of Science and Technology Co., Ltd. (Beijing, China). TaKaRa RNA PCR Kit (AMV) Ver.3.0 and EX TAQ R-PCR Version 2.1 were purchased from TaKaRa Biomedical Technology (Beijing, China). TRIzol reagent of Invitrogen was obtained from Thermo Fisher Scientific (Shanghai, China). Asarinin was obtained from Chengdu Must Bio-Technology Co., Ltd. (Chengdu, China). Primers and probes were purchased from Pharmacia Biotech (Roosendaal, Netherlands); Q-plex array was obtained from Beijing Taize Ruida Technology (Beijing, China). CD11c MicroBeads was obtained from Beijing Beads Biotechnologies Co., Ltd. (Beijing, China).

Induction of CIA On day 1, the mice were immunized with $100 \mu \mathrm{L}$ of emulsion ( $100 \mu \mathrm{g}$ of bovine type II collagen) at the base of the tail after the bovine type II collagen was emulsified with FCA (1:1 vol), and the intraperitoneal injection was administered to the animals with $100 \mu \mathrm{g}$ of bovine type II collagen on day 21.5)

Treatment Protocol To study the curative effects of asarinin on RA, CIA mice without symptoms of arthritis on the 21st day following the administration of control, asarinin and Methotrexate (MTX) groups randomly. Asarinin was administered orally to mouse once every $2 \mathrm{~d}$ for $60 \mathrm{~d}$ at dosage of $4 \mathrm{mg} / \mathrm{kg}$, MTX were injected intraperitoneally daily for $60 \mathrm{~d}$ at dosage of $0.2 \mathrm{mg} / \mathrm{kg}$, and phosphate buffered saline (PBS) without collagen II was administered orally to model group and blank group. Two independent observers performed erythema and swelling scores on the mice every other day.

Assessment of CIA Arthritis responses was assessed from day 1 of the second immunization, and arthritis was judged visually by redness or swelling of the toes, ankles and knees. Arthritis scoring criteria were from the paper described previously. Arthritis scores were $0,0.25$ or 0.5 , respectively, depending on the onset of arthritis, the number of joints involved in arthritis, and the severity of the arthritis. Two independent observers performed erythema and swelling scores on the mice every other day. Two independent observers performed erythema and swelling scores on the mice every other day, and the foot depth was measured every six day. ${ }^{14-16)}$

Histology The mice were anesthetized and killed by ether. Knee joints were removed and fixed in $4 \%$ formalin for $4 \mathrm{~d}$. After $5 \%$ decalcification of formate, the sample was treated for paraffin embedding. Hematoxylin and eosin (H\&E) or Van Gieson stain were used to stain tissue sections (7 pans). The occurrence of cartilage damage and bone erosion was detected by histopathology. ${ }^{15,16)}$

Cytokines Measurement of Hindpaw Mice were sacrificed after anesthesia. The hind paws were removed and the protein extracts of the hind paws were homogenized by mixing the joints of dithiothreitol (DTT) and protease inhibitors. According to the manufacturer's instructions, the level of cytokines in the hindpaw protein extract was detected using a Q-plex array by a sandwich enzyme-linked immunosorbent assay (ELISA).

CD11c + DCs Acquisition After the CIA mice were anesthetized and killed, the spleen of mice was taken and grounded with 200 mesh stainless steel to obtain spleen cell suspension. CD11c + DCs cells were isolated from the suspen-
Table 1. Primers and Sequence

\begin{tabular}{|c|c|c|}
\hline Gene & & Primers \\
\hline \multirow[t]{2}{*}{$\beta$-Actin } & Sense & $5^{\prime}$ tgg aat cet gtg gca tcc atct aaa c $3^{\prime}$ \\
\hline & Antisense & $5^{\prime}$ taa aac gca get cag taa cag tcc g $3^{\prime}$ \\
\hline \multirow[t]{2}{*}{ IL-12 } & Sense & $5^{\prime}$ gac cet gec cat tga act ggc $3^{\prime}$ \\
\hline & Antisense & $5^{\prime}$ caa cgt tgc atc cta gga tcg $3^{\prime}$ \\
\hline \multirow[t]{2}{*}{ IL-10 } & Sense & $5^{\prime}$ gaa gac cet cag gat gcg $3^{\prime}$ \\
\hline & Antisense & $5^{\prime}$ cca agg agt tgt ttc cgt ta $3^{\prime}$ \\
\hline \multirow[t]{2}{*}{$\mathrm{TNF}-\alpha$} & Sense & $5^{\prime}$ ctg tga agg gaa tgg gtg tt $3^{\prime}$ \\
\hline & Antisense & $5^{\prime}$ cag gga aga gtc tgg aaa ggt $3^{\prime}$ \\
\hline \multirow[t]{2}{*}{ IL-18 } & Sense & $5^{\prime}$ acc gaa ttc act gta caa ccg cag taa tac gga $3^{\prime}$ \\
\hline & Antisense & $5^{\prime}$ gec tct aga gtg aac att aca gat tta tcc cca $3^{\prime}$ \\
\hline \multirow[t]{2}{*}{ TGF- $\beta$} & Sense & $5^{\prime}$ aaa cgg aag cgc atc gaa $3^{\prime}$ \\
\hline & Antisense & $5^{\prime}$ ggg act gge gag cet tag tt $3^{\prime}$ \\
\hline \multirow[t]{2}{*}{ t-bet } & Sense & $5^{\prime}$ tca cta agc aag gac ggc gaa t $3^{\prime}$ \\
\hline & Antisense & $5^{\prime}$ gcc tct ggc tct cca tca ttc a $3^{\prime}$ \\
\hline \multirow[t]{2}{*}{ GATA-3 } & Sense & $5^{\prime}$ cet tat caa gcc caa gcg aa $3^{\prime}$ \\
\hline & Antisense & $5^{\prime}$ gge tct gec tct cta acc ca $3^{\prime}$ \\
\hline \multirow[t]{2}{*}{ FOX-P3 } & Sense & $5^{\prime}$ tca agt acc aca ata tgc gac cc $3^{\prime}$ \\
\hline & Antisense & $5^{\prime}$ gtg gcg gat ggc att ctt c $3^{\prime}$ \\
\hline \multirow[t]{2}{*}{ TLR-9 } & Sense & $5^{\prime}$ atg gtt ctc cgt cga agg act $3^{\prime}$ \\
\hline & Antisense & $5^{\prime}$ gag get tca get cac agg g $3^{\prime}$ \\
\hline \multirow[t]{2}{*}{$\mathrm{NF}-\kappa \mathrm{B}$} & Sense & $5^{\prime}$ gga ggc atg ttc ggt agt gg $3^{\prime}$ \\
\hline & Antisense & $5^{\prime} \mathrm{ccc}$ tgc gtt gga ttt $\operatorname{cgt} \mathrm{g} 3^{\prime}$ \\
\hline \multirow[t]{2}{*}{ ICAM-1 } & Sense & $5^{\prime}$ gtg atg ctc agg tat cca tcc a $3^{\prime}$ \\
\hline & Antisense & $5^{\prime}$ cac agt tct caa agc aca geg $3^{\prime}$ \\
\hline \multirow[t]{2}{*}{ OX40L } & Sense & $5^{\prime}$ aat ctg gaa aac gga tca agg c $3^{\prime}$ \\
\hline & Antisense & $5^{\prime}$ cag gca gac ata gat gaa gca c $3^{\prime}$ \\
\hline \multirow[t]{2}{*}{ 4-1BBL } & Sense & $5^{\prime} \operatorname{cgg} \mathrm{cgc}$ tcc tca gag ata c $3^{\prime}$ \\
\hline & Antisense & $5^{\prime}$ atc ccg aac att aac cgc agg $3^{\prime}$ \\
\hline
\end{tabular}

sion of spleen cells using CD11c MicroBeads according to the manufacturer's instructions. ${ }^{17)}$

RT-PCR and Quantitative PCR CIA mice were sacrificed after anesthesia, RNA was obtained from synovium and CD11c+ cell suspension. RT-PCR and quantitative PCR were used to amplify related cytokines in synovium of CIA, ${ }^{1,14-16)}$ and the expression of toll-like receptor 9 (TLR-9)-9, nuclear factor-kappaB $(\mathrm{NF}-\kappa \mathrm{B})$ and adhesion molecules and costimulatory molecules on the surface of DCs was determined by Quantitative RT-PCR. ${ }^{18)}$ Primers for IL-12, TGF- $\beta$, IL-18, Foxp3, TNF- $\alpha$, TLR9, IL-10, NF- $\kappa$ B, T-bet, intercellular cell adhesion molecule-1 (ICAM-1), GATA-3, OX-40L, and 4-1BBL genes sequences for PCR were from the paper described previously or systhesized by Pharmacia Biotech. ${ }^{1,14,19)}$ Primers sequences were shown in Table 1. RT-PCR and quantitative PCR were performed according to the manufacturer's instructions.

Statistical Analysis Data are presented as the means \pm standard deviations (S.D.s). The statistical significance of differences was analyzed by Student's $t$ test, Wilcoxon rank test, and one-way ANOVA, and a $p$ value below 0.05 was considered significant.

\section{RESULTS}

Therapeutic Role of Asarinin in Collagen-induced Arthritis CIA mice were treated with asarinin before the onset of arthritis, and CIA mice without arthritic symptoms were chose for experiment on the 21st day of immunization. 

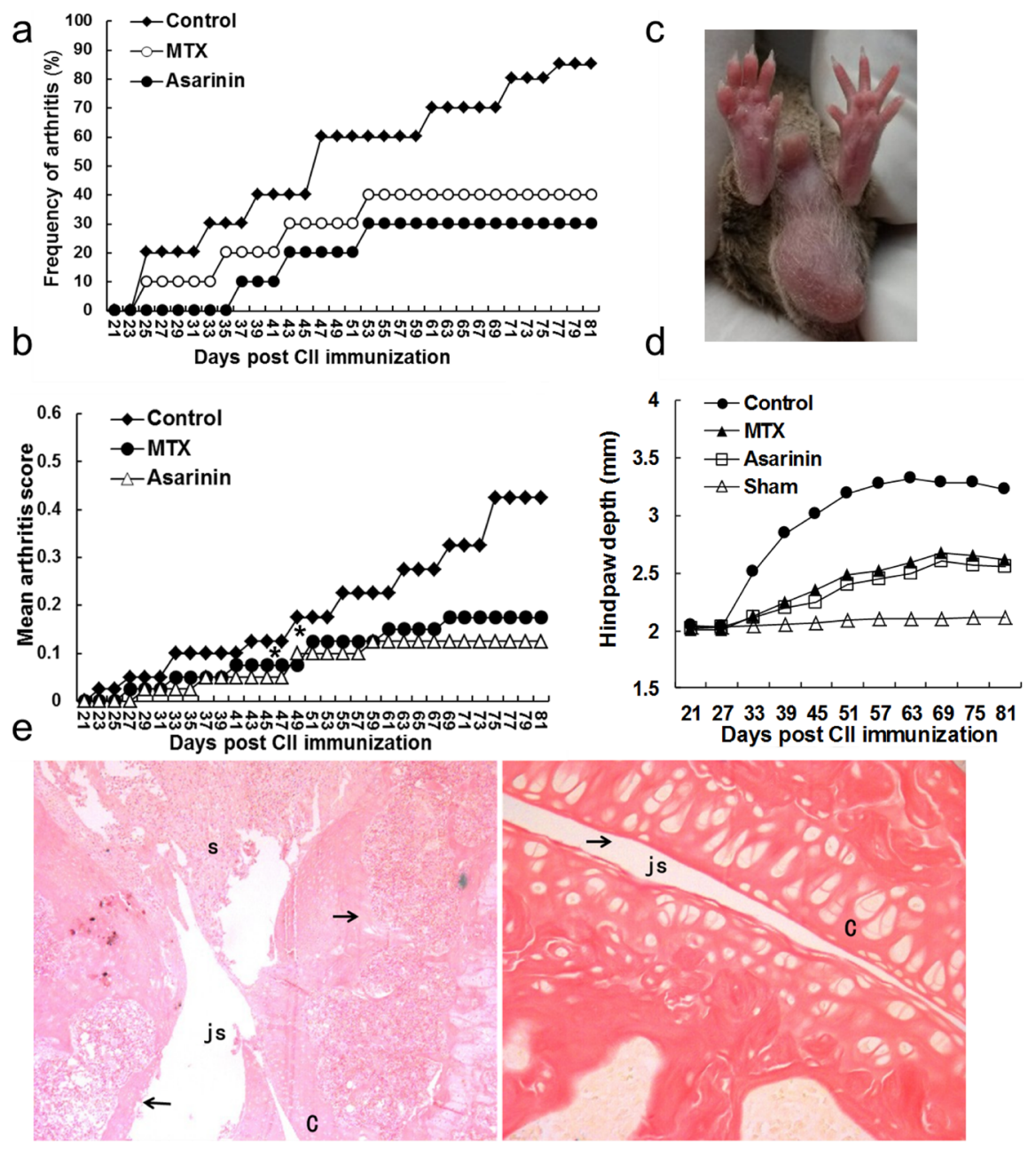

Fig. 1. Therapeutic Effect of Asarinin

(a) Frequency of arthritis. (b) Clinical arthritis score. The mean macroscopic score and frequency of arthritis were monitored throughout the study, with data representing arthritis score and the average incidence of arthritis in each group.*indicates $p<0.05$ between dose group (asarinin or MTX) and model control groups by Wilcoxon rank test. (c) Paw swelling of control group. (d) The thickness of hindpaw of each group. The hindpaw depth was measured by micrometer caliper every six days to observe the effect of asarinin on arthritis responses. (e) Representative histological findings in the knee joint of CIA mice after asarinin treatment. H\&E or Van Gieson stain was used to stain knee joint of CIA collected on day 81. Left: Severe cartilage surface disruption, infiltrate of inflammatory cells, and bone erosion were found in model control group (arrows). Right: CIA mice of asarinin group, the intact cartilage surface is shown to be significantly improved (arrows). Note: $\mathbf{C}$ : cartilage, js: joint space, $\mathbf{s}$ : Synovium Left $(\times 10$ by H\&E), right $(\times 40$ by Van Gieson stain). (Color figure can be accessed in the online version.)

Asarinin inhibited the onset of CIA and arthritis symptoms of CIA, and the mean arthritis score and frequency of arthritis significantly decreased than those in control (Figs. 1a, 1b). The animals in the model control group showed more extreme symptoms than those in the treatment group (Fig. 1c). Joint thickness (paw swelling) significantly decreased than that in control after asarinin treatment (Fig. 1d). Infiltration of inflammatory cells in the knee and destruction of bone and cartilage were significantly improved in the asarinin treatment group (Fig. 1e) (Table 2).

Cytokine Protein Expression in the Hindpaw Cytokine protein extracts of the hind paws from CIA mice are presented in Fig. 2. A significant decrease was observed in levels of TNF- $\alpha$, IL-12 and IL-18 in the asarinin-treated mice compared with that of vehicle-treated animals. After asarinin treatment, levels of TGF- $\beta$, IL-10 and Foxp3 increased even more impressively (Fig. 2).

Asarinin Inhibits CIA by Skewing the Balance of Th1/Th2/Treg to a Th2 Type In order to further clarify the Th1/Th2/Treg cells in collagen induced arthritis after the treatment of asarinin, mRNA of Th1/Th2/Treg cells related
Table 2. Histology of Knee Joints after Asarinin Treatment

\begin{tabular}{lccc}
\hline \hline Group & Infiltrate & Cartilage destruction & Bone erosion \\
\hline Control & $1.2 \pm 0.5$ & $1.1 \pm 0.3$ & $1.9 \pm 0.7$ \\
MTX & $0.7 \pm 0.5^{*}$ & $0.21 \pm 0.3^{*}$ & $0.68 \pm 0.23^{*}$ \\
Asarinin & $0.9 \pm 0.4$ & $0.19 \pm 0.28^{*}$ & $0.57 \pm 0.37^{*}$ \\
Sham & 0 & 0 & 0 \\
\hline
\end{tabular}

Note: ${ }^{*} p<0.05$ versus controls. $(\bar{x} \pm s, n=5)$

cytokines was extracted from synovial tissue and patellar cartilage on day 81. Cytokine and transcription factor mRNA expression were determined by RT-PCR (Fig. 3a) and quantitative RT-PCR (Fig. 3b) as shown in Fig. 3. TNF- $\alpha$, IL-12 and IL-18 were significantly reduced in asarinin-treated mice compared to the control group. Increased IL-10 and TGF- $\beta$ mRNA levels were even more impressive (Figs. 3a, 3b). The expression of Foxp3 was up-regulated after asarinin treatment. A series of intracellular transcription factors is activated, resulting in helper T-cell activation and the differentiation of Th1/Th2, so GATA-3 and T-bet in the synovium were tested. 

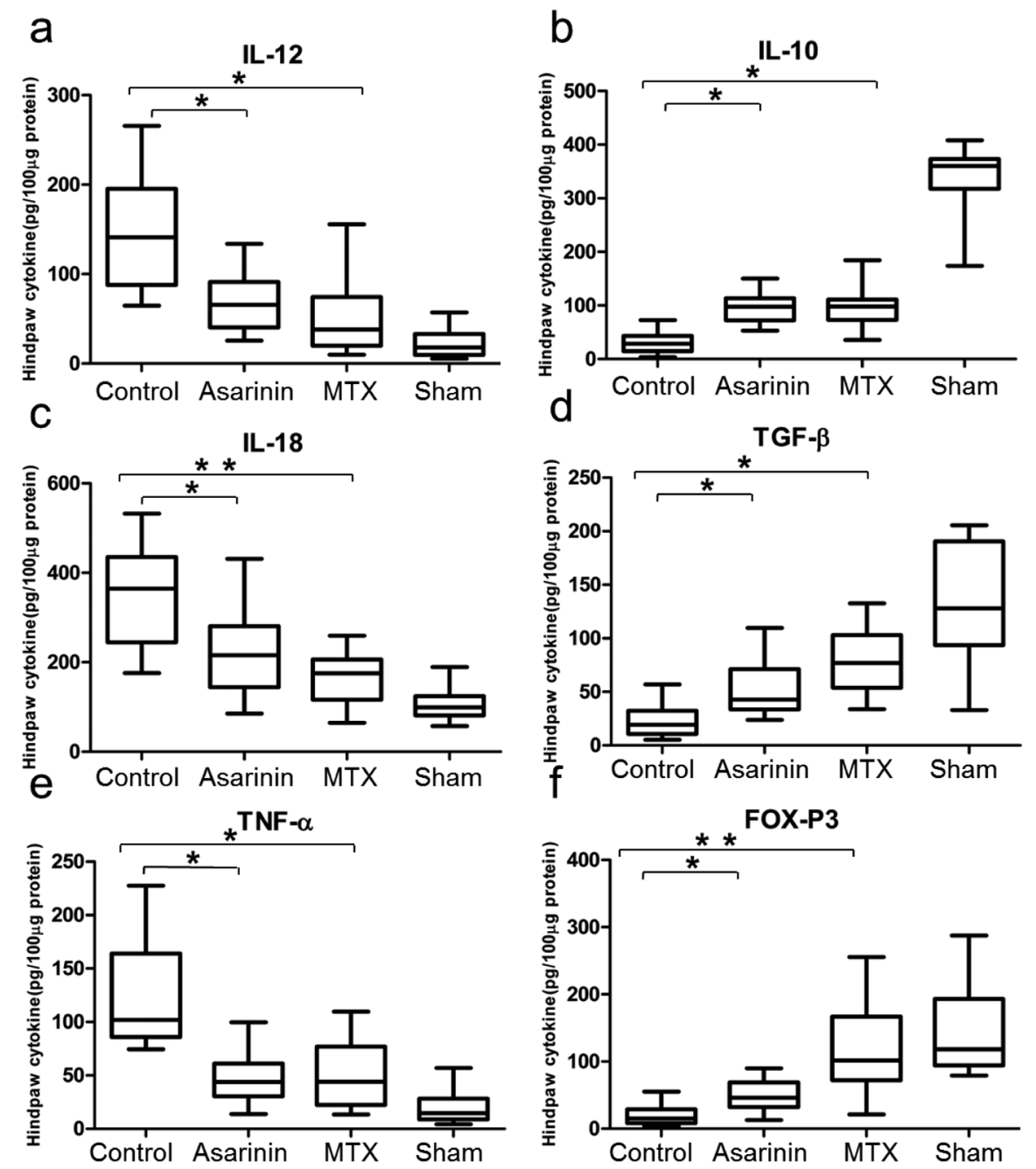

Fig. 2. Regulation of Cytokine Secretion in the Hindpaw in Asarinin-Treated Mice

Levels of IL-12, IL-18, TNF- $\alpha$, IL-10, TGF- $\beta$, and Fox-P3 were determined by using ELISA kits. *indicates $p<0.05$ or $* *$ indicates $p<0.01$ between treated (asarinin or MTX) and model control groups by one-way ANOVA.

GATA-3 mRNA expression was not different between the two groups (data not shown). However, T-bet mRNA expression was significantly lower in the asarinin-treated mice than in the control group (Figs. 3a, 3b).

DCs Surface Molecules Expression To illustrate the mechanism of DCs in treatment of CIA with asarinin, we investigated DCs surface molecules expression (Fig. 4). The lower expression of TLR 9 and NF- $\kappa \mathrm{B}$ was found in asarinin group when compared with model control group, and the expression of ICAM-1, OX40L, and 4-1BBL was not significantly different (Fig. 4).

\section{DISCUSSION}

There were significant differences in the asarinin-treated group compared with the control group with respect to mean macroscopic score, frequency of arthritis, swelling of hind paws and the degree of histopathological progress. No significant difference was observed between the asarinin-treated group and MTX-treated group. MTX, a cytotoxic immunosuppressant, was first used to treat tumors in the $1820 \mathrm{~s}$, and was used to treat RA in the $1850 \mathrm{~s}$. MTX is an anti-rheumatoid drug with an obvious curative effect that plays an important role in the treatment of RA. MTX relieves arthritis by preventing or slowing the destruction of articular cartilage and bone. Asarinin had a definite therapeutic effect on collageninduced arthritis.

The incidence of RA is related to T cell immune abnormalities. $\mathrm{T}$ cells can be classified into helper $\mathrm{T}$ cells, such as Th1 cells and Th2 cells, cytotoxic $\mathrm{T}$ cells, and regulatory $\mathrm{T}$ cells, according to immune effector functions. Th1, Th2, or Treg cells are activated by the initial $\mathrm{CD}^{+} \mathrm{T}$ cell differentiation, and they become functionally and phenotypically different effector T cells. ${ }^{20-22)}$ There are local responses in RA patients with inflamed joints that are Th1-dominant and Th2 deficient. RA is thought to be a disease mediated by the Th1 immune response. ${ }^{23)}$ On the other hand, Treg cells infiltrate the synovial tissue of RA patients, and this infiltration is associated with RA diseases activity. Treg cells in patients with RA are fewer in number and function abnormally. ${ }^{24,25)}$ Inflammatory cytokines in RA are selectively recruited into the joint cavity, so this study examined various cytokines in the hindpaw and synovium. $^{23,26)}$ Asarinin, like MTX, significantly reduced the expression levels of IL-18, IL-12 and TNF- $\alpha$ in the hindpaw and synovium. However, the levels of Th2 cytokines (IL-10) were up-regulated, and Foxp3 expression and TGF- $\beta$ expres- 
a

b
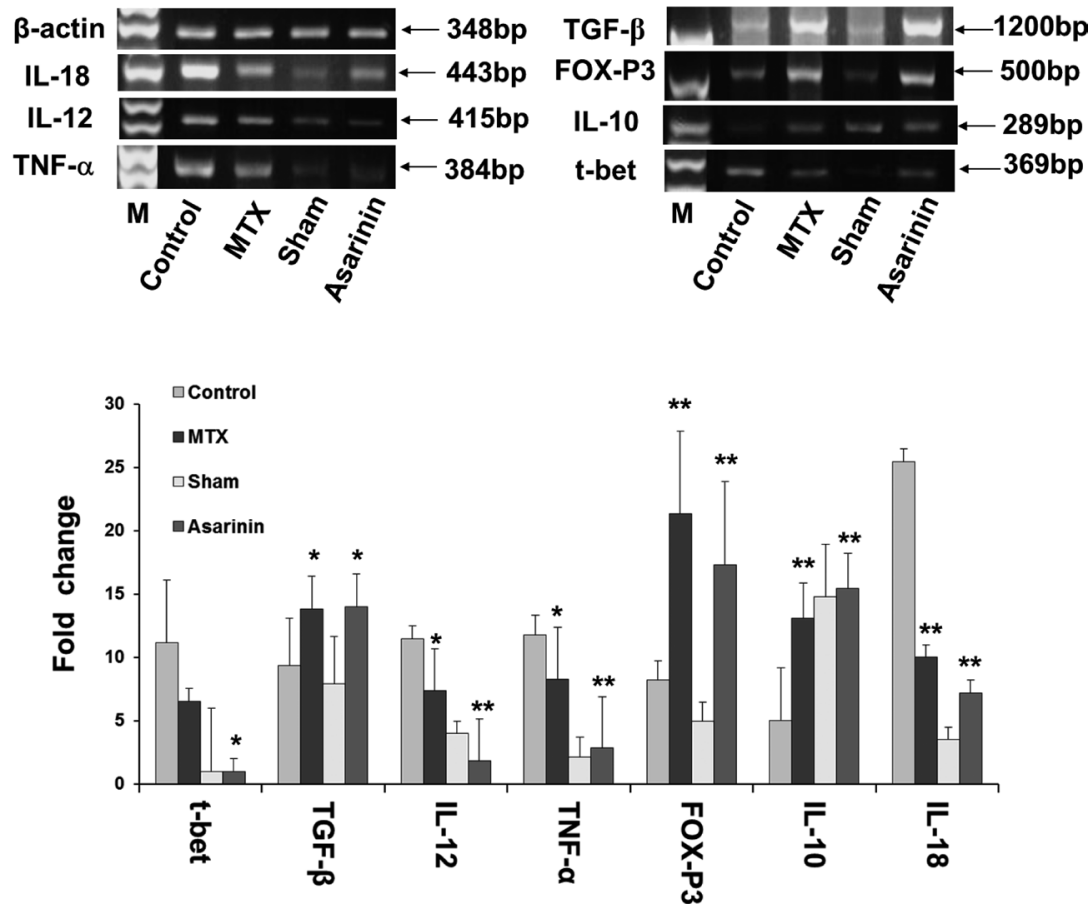

Fig. 3. Cytokine and Transcription Factor Expression in the Joint of Knee

(a) Detection of expression of cytokines and transcription factors in knee joints by RT-PCR. On day 81, total RNA was extracted from synovial tissue of five CIA mice per experimental group, RT-PCR was used to determine the expression of IL-18, IL-10, Fox-P3, TNF- $\alpha$, IL-12, TGF- $\beta$, and T-bet, and with $\beta$-actin as loading control. (b) Detection of expression of cytokines and transcription factors in knee joints by quantitative RT-PCR. Quantitative RT-PCR was employed to determine the expression of IL-12, IL-18, TNF- $\alpha$, IL-10, TGF- $\beta$, Fox-P3, and T-bet, and with $\beta$-actin as loading control. The relative expressions of IL-12, IL-18, TNF- $\alpha$, IL-10, TGF- $\beta$, Fox-P3, and t-bet were obtained from three-separated quantitative RT-PCR analysis (mean \pm standard error (S.E.)), expressed by density histogram data. $*$ indicates $p<0.05$ or $* *$ indicates $p<0.01$ between treated (asarinin or MTX) and model control groups by Student's $t$ test.

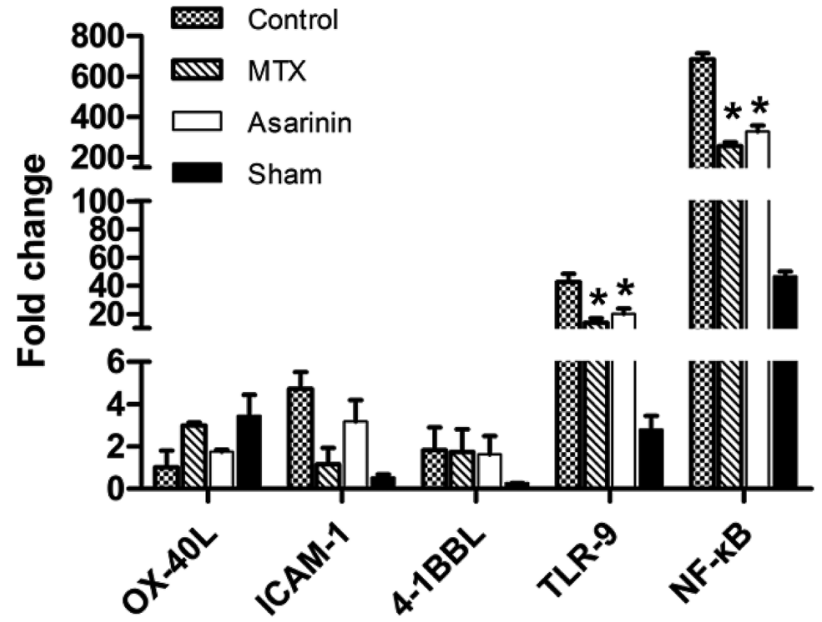

Fig. 4. Effect of Asarinin on Expression of Surface Signaling Pathways Molecules of DCs

The density histogram data showing changes in the expression of ICAM-1, OX40L, 4-1BBL, TLR9 and NF- $\kappa$ B in DCs of spleen, determined by quantitative PCR analysis at $81 \mathrm{~d}$ after immunization. ${ }^{*} p<0.05 \mathrm{vs}$. control by Student's $t$ test.

sion in synovial membrane tissue and hindpaw increased. The levels of Th2 cytokines (IL-4 and IL-5) were not amplified by RT-PCR and quantitative PCR (data not shown). A series of intracellular transcription factors is activated, resulting in helper T-cell activation and the differentiation of Th1/Th2, so GATA-3 (Th2-specific transcription factor) and T-bet (Th1specific transcription factor) in the synovium were tested. The results showed that while the levels of GATA-3 were not significantly different among the groups (data not shown), the levels of T-bet were significantly lower in the asarinin group than in the control group. The evidence suggested that in the asarinin group, the activation of the Th1 immune response was inhibited through inhibition of the transcription factor T-bet.

Foxp3 is essential for T-cell homeostasis and is specifically expressed by regulatory $\mathrm{T}$ cells in the body. ${ }^{27,28)} \mathrm{The}$ immunosuppression of Treg cells relies on a large quantity of cytokines such as IL-10 and TGF- $\beta .^{29)}$ The PCR results showed that asarinin significantly increased the expression levels of TGF- $\beta$ and FOXP3 in the synovium. Regulatory Th2 gene expression was inhibited when GATA-3 combined with FoxP3. The level of GATA-3 decreased as the level of FOXP3 increased due to the interaction of GATA-3 with FOXP3. ${ }^{30-32)}$ IL-10 and TGF- $\beta$ expression levels increased after asarinin treatment, which promoted Treg cells by activating the transcription factor FOXP3. The treatment with asarinin increased the number of Treg cells and inhibited the development of inflammation in collagen-induced arthritis.

ICAM-1 is both a cell surface glycoprotein and a costimulatory molecule of the immunoglobulin superfamily, providing signals for cytotoxic $\mathrm{T}$ lymphocytes and natural killer (NK) cells. ICAM-1 and vascular cell adhesion molecule-1 (VCAM-1) contribute to angiogenesis and leukocyte migration in RA synovial tissue. ${ }^{33)}$ The TNF/TNFR family members include 4-1BB/4-1BBL, CD27/CD70, ICOS/ICOSL, and OX40/ OX40L, which have been reported to play an important role in T cell activation. ${ }^{34)} \mathrm{OX}-40$ is originally thought to be a surface marker activation of CD4 $+\mathrm{T}$ cells in rats, ${ }^{35)}$ which is mainly induced at the effector stage of $\mathrm{T}$ cells and is mainly expressed 
on Th2 cells. ${ }^{36)}$ Dendritic cells express TLR9 in cells and specifically identify non-methylated $\mathrm{CpG}$ motifs, which has been shown to promote Th1 immune responses in L. major-infected susceptible mice. TLR9 promotes the expression of inflammatory cytokines by activating NF- $\kappa \mathrm{B} .{ }^{37)}$ Previous studies have confirmed that the production of $\mathrm{CD} 4+\mathrm{CD} 25+$ regulatory $\mathrm{T}$ cells was induced by human plasmacytoid DCs activated by CpG oligonucleotide. ${ }^{38)}$ Lupus is prevented by TLR9 signaling by regulating the activity of regulatory $\mathrm{T}$ cells. ${ }^{39,40)}$ Pyrrolidine dithiocarbamate (PDTC) is inhibitor of NF- $\kappa$ B. Experimental autoimmune uveoretinitis (EAU) is a $\mathrm{T}$ helper type 1 cell-mediated autoimmune disease. EAU can be inhibited by PDTC. ${ }^{41)}$ E6446 is inhibitor of TLR9. E6446 can alleviate the disease of spontaneous mouse lupus model. ${ }^{42)}$ Lower expression of TLR9 and NF-kB were found in asarinin group in our study. Although the mechanism of action of methotrexate in the treatment of RA has not yet been fully understood, it is recognized as one of the most effective Disease-modifying anti-rheumatic drugs (DMARD) because of its quick effect, convenient administration, mild side effects and no long-term carcinogenic effects, and related studies have confirmed that MTX can regulate the balance of Th1/Th2/Treg to treat experimental RA. ${ }^{43)}$ Asarinin maybe inhibit CIA by skewing the balance of Th1/Th2/Treg to a Th2 type through inhibiting the activation of TLR9/NF- $\kappa$ B pathway.

Acknowledgments This work was supported by the Fund of Heilongjiang Science and Technical Office (QC2011C059), Harbin Science and Technology Bureau of Heilongjiang Province (2012RFQXS020), Postdoctoral Foundation of China and Heilongjiang Province (2013M531081, LBH-Z11004, LBH-Q15138). Excellent Innovative Talents Support Project of Heilongjiang University of Traditional Chinese Medicine (Excellent Young Academic Leader).

Conflict of Interest The authors declare no conflict of interest.

\section{REFERENCES}

1) Dai Q, Li Y, Zhang F, Yu H, Wang X. Therapeutic effect of lowdose IL-18 combined with IL-10 on collagen-induced arthritis by down-regulation of inflammatory and Th1 responses and induction of Th2 responses. Rheumatol. Int., 29, 615-622 (2009).

2) Guggino G, Giardina AR, Raimondo S, Giardina G, Sireci G, Diel F, Peralta M, Alessandro R, Triolo G, Ciccia F. Targeting IL-6 signalling in early rheumatoid arthritis is followed by Th1 and Th17 suppression and Th2 expansion. Clin. Exp. Rheumatol., 32, 77-81 (2014).

3) Gonzalo-Gil E, Criado G, Santiago B, Dotor J, Pablos JL, Galindo M. Transforming growth factor (TGF) $\beta$ signalling is increased in rheumatoid synovium but TGF- $\beta$ blockade does not modify experimental arthritis. Clin. Exp. Immunol., 174, 245-255 (2013).

4) Thepmalee C, Panya A, Junking M, Chieochansin T, Yenchitsomanus PT. Inhibition of IL-10 and TGF- $\beta$ receptors on dendritic cells enhances activation of effector T-cells to kill cholangiocarcinoma cells. Hum. Vaccin. Immunother., 14, 1423-1431 (2018).

5) Brand DD, Latham KA, Rosloniec EF. Collagen-induced arthritis. Nat. Protoc., 2, 1269-1275 (2007).

6) Schurgers E, Billiau A, Matthys P. Collagen-induced arthritis as an animal model for rheumatoid arthritis: focus on interferon- $\gamma . J$. Interferon Cytokine Res., 31, 917-926 (2011).

7) Hirose J, Tanaka S. Animal models for bone and joint disease. CIA,
CAIA model. Clin. Calcium, 21, 253-259 (2011).

8) Marcińska K, Szczepanik M. Mechanisms involved in the regulation of immune response in animal model of rheumatoid arthritis in mice (CIA). Postepy Hig. Med. Dosw. (online), 64, 372-385 (2010).

9) Park HJ, Lee KS, Zhao TT, Lee KE, Lee MK. Effects of asarinin on dopamine biosynthesis and 6-hydroxydopamine-induced cytotoxicity in PC12 cells. Arch. Pharm. Res., 40, 631-639 (2017).

10) Gu J, Zhang L, Wang $Z$, Chen $Y$, Zhang G, Zhang D, Wang $X$, Bai $\mathrm{X}, \mathrm{Li} \mathrm{X}$, Lili Z. The effect of Asarinin on Toll-like pathway in rats after cardiac allograft implantation. Transplant. Proc., 47, 545-548 (2015)

11) Jing Y, Zhang YF, Shang MY, Liu GX, Li YL, Wang X, Cai SQ. Chemical constituents from the roots and rhizomes of Asarum heterotropoides var. Mandshuricum and the in vitro anti-inflammatory activity. Molecules, 22, 125 (2017)

12) Zhang LL, Lu SF, Zhang S, Nie HG, Guan ZZ, Yang BF. Effect of asarinin on the acute heart transplantation rejection and the expression of adhesion molecule. Chung Kuo Chung Yao Tsa Chih, 31, 494-497 (2006).

13) Xiong Y, Jing Y, Shang M, Li C, Ye J, Wang X, Cai S. Anti-inflammatory and anti-nociceptive effects in mice of water and ethanol extracts of roots and rhizomes of Asarum heterotropoides var. mandshuricum. Zhongguo Zhong Yao Za Zhi, 34, 2252-2257 (2009).

14) Dai Q, Fang J, Zhang F. Dual role of shikonin in early and late stages of collagen type II arthritis. Mol. Biol. Rep., 36, 1597-1604 (2009).

15) Yamaguchi Y, Fujio K, Shoda H, Okamoto A, Tsuno NH, Takahashi K, Yamamoto K. IL-17B and IL-17C are associated with TNF-alpha production and contribute to the exacerbation of inflammatory arthritis. J. Immunol., 179, 7128-7136 (2007).

16) Banda NK, Kraus DM, Muggli M, Bendele A, Holers VM, Arend WP. Prevention of collagen-induced arthritis in mice transgenic for the complement inhibitor complement receptor 1-relatedgene/ protein. J. Immunol., 171, 2109-2115 (2003).

17) Liu M, Wang P, Zhao M, Liu DY. Intestinal dendritic cells are altered in number, maturity and chemotactic ability in fulminant hepatic failure. PLOS ONE, 11, e0166165 (2016).

18) van Hamburg JP, Asmawidjaja PS, Davelaar N, Mus AMC, Colin EM, Hazes JMW, Dolhain RJEM, Lubberts E. Th17 cells, but not th1 cells, from patients with early rheumatoid arthritis are potent inducers of matrix metalloproteinases and proinflammatory cytokines upon synovial fibroblast interaction, including autocrine interleukin17a production. Arthritis Rheum., 63, 73-83 (2011).

19) Dai Q, Li J, Yun Y, Wang J. Toll-like receptor 4-myeloid differentiation primary response gene 88 pathway is involved in the shikonin treatment of cia by regulating Treg/th17 expression. Evid. Based Complement. Alternat. Med., 2018, 2428546 (2018).

20) Caza T, Landas S. Functional and phenotypic plasticity of CD4(+) T cell subsets. Biomed Res Int., 2015, 521957 (2015).

21) Youngblood B, Hale JS, Ahmed R. Memory CD8 T cell transcriptional plasticity. F1000Prime Rep., 7, 38 (2015).

22) Srenathan U, Steel K, Taams LS. IL-17+ CD8+ T cells: differentiation, phenotype and role in inflammatory disease. Immunol. Lett., 178, 20-26 (2016).

23) Mellado M, Martínez-Muñoz L, Cascio G, Lucas P, Pablos JL, Rodríguez-Frade JM. T cell migration in rheumatoid arthritis. Front. Immunol., 6, 384 (2015).

24) Humrich JY, Kamradt T, Riemekasten G. Regulatory $T$ cells and rheumatic diseases. Z. Rheumatol., 74, 26-32 (2015).

25) Byng-Maddick R, Ehrenstein MR. The impact of biological therapy on regulatory $\mathrm{T}$ cells in rheumatoid arthritis. Rheumatology $(\mathrm{Ox}-$ ford), 54, 768-775 (2015)

26) Millán $\mathrm{O}$, Brunet M. Cytokine-based immune monitoring. Clin. Biochem., 49, 338-346 (2016).

27) Chen W, Konkel JE. Development of thymic Foxp3(+) regulatory $T$ cells: TGF- $\beta$ matters. Eur. J. Immunol., 45, 958-965 (2015). 
28) Li Z, Li D, Tsun A, Li B. FOXP3+ regulatory T cells and their functional regulation. Cell. Mol. Immunol., 12, 558-565 (2015).

29) Komai T, Okamura T, Yamamoto K, Fujio K. The effects of TGF- $\beta$ s on immune responses. Nihon Rinsho Meneki Gakkai Kaishi, 39, 51-58 (2016)

30) Newton R, Priyadharshini B, Turka LA. Immunometabolism of regulatory T cells. Nat. Immunol., 17, 618-625 (2016).

31) Panduro M, Benoist C, Mathis D. Tissue Tregs. Annu. Rev. Immunol., 34, 609-633 (2016).

32) Rothstein DM, Camirand G. New insights into the mechanisms of Treg function. Curr. Opin. Organ Transplant., 20, 376-384 (2015).

33) Amin MA, Campbell PL, Ruth JH, Isozaki T, Rabquer BJ, Stinson WA, O’Brien M, Edhayan G, Ohara RA, Vargo J, Domino SE, Koch AE. A key role for Fut1-regulated angiogenesis and ICAM-1 expression in $\mathrm{K} / \mathrm{BxN}$ arthritis. Ann. Rheum. Dis., 74, 1459-1466 (2014).

34) Zeng W, Su M, Anderson KS, Sasada T. Artificial antigen-presenting cells expressing CD80, CD70, and 4-1BBligand e-fficiently expand functional $\mathrm{T}$ cells specific totumor-associated antigens. Immunobiology, 219, 583-592 (2014).

35) Moran AE, Kovacsovics-Bankowski M, Weinberg AD. The TNFRs OX40, 4-1BB, and CD40 as targets for cancer immunotherapy. Curr. Opin. Immunol., 25, 230-237 (2013).

36) Siddiqui S, Mistry V, Doe C, Stinson S, Foster M, Brightling C. Airway wall expression of ox40/ox401 and interleukin-4 in asthma. Chest, 137, 797-804 (2010).

37) Dai Q, Li Y, Yu H, Wang X. Suppression of Th1 and Th17 responses and induction of Treg responses by IL-18-expressing plasmid gene combined with IL-4 on collagen-induced arthritis. Biomed Res Int, 2018, 5164715 (2018).

38) Carranza F, Falcón CR, Nuñez N, Knubel C, Correa SG, Bianco I, Maccioni M, Fretes R, Triquell MF, Motrán CC, Cervi L. Helminth antigens enable $\mathrm{CpG}$-activated dendritic cells to inhibit the symptoms of collagen-induced arthritis through Foxp3+ regulatory $\mathrm{T}$ cells. PLOS ONE, 7, e40356 (2012).

39) Hackl D, Loschko J, Sparwasser T, Reindl W, Krug AB. Activation of dendritic cells via TLR7 reduces Foxp3 expression and suppressive function in induced Tregs. Eur. J. Immunol., 41, 1334-1343 (2011).

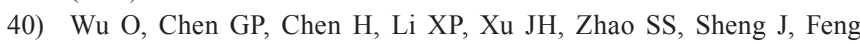
JB, Cai J, Fang XH, Zhang WH, Li LH, Zhang N, Li J, Li JJ, Pan FM, Wang CZ, Ye DQ. The expressions of Toll-like receptor 9 and T-bet in circulating $\mathrm{B}$ and $\mathrm{T}$ cells in newly diagnosed, untreated systemic lupus erythematosus and correlations with disease activity and laboratory data in a Chinese population. Immunobiology, 214, 392-402 (2009).

41) Kitamei H, Iwabuchi K, Namba K, Yoshida K, Yanagawa $Y$, Kitaichi N, Kitamura M, Ohno S, Onoé K. Amelioration of experimental autoimmune uveoretinitis (EAU) with an inhibitor of nuclear factor-kappaB (NF-kappaB), pyrrolidine dithiocarbamate. J. Leukoc. Biol., 79, 1193-1201 (2006).

42) Lamphier M, Zheng W, Latz E, Spyvee M, Hansen H, Rose J, Genest M, Yang H, Shaffer C, Zhao Y, Shen Y, Liu C, Liu D, Mempel TR, Rowbottom C, Chow J, Twine NC, Yu M, Gusovsky F, Ishizaka ST. Novel small molecule inhibitors of TLR7 and TLR9: mechanism of action and efficacy in vivo. Mol. Pharmacol., 85, 429-440 (2014).

43) Xinqiang S, Fei L, Nan L, Yuan L, Fang Y, Hong X, Lixin T, Juan L, Xiao Z, Yuying S, Yongzhi X. Therapeutic efficacy of experimental rheumatoid arthritis with low-dose methotrexate by increasing partially CD4+ CD25+ Treg cells and inducing Th1 to Th2 shift in both cells and cytokines. Biomed. Pharmacother., 64, $463-471$ (2010). 